\title{
BERTRAND (Jean-René), MULLER (Colette), éds., Religions et territoires
}

Paris, L'Harmattan, 1999, 290 p.

Danièle Hervieu-Léger

\section{(2) OpenEdition}

\section{Journals}

Édition électronique

URL : http://journals.openedition.org/assr/20858

DOI : $10.4000 /$ assr.20858

ISSN : $1777-5825$

\section{Éditeur}

Éditions de l'EHESS

Édition imprimée

Date de publication : 1 juin 2001

Pagination : 129-130

ISBN : 2-222-96704-X

ISSN : 0335-5985

\section{Référence électronique}

Danièle Hervieu-Léger, «BERTRAND (Jean-René), MULLER (Colette), éds., Religions et territoires », Archives de sciences sociales des religions [En ligne], 114 | avril-juin 2001, document 114.58, mis en ligne le 19 août 2009, consulté le 21 septembre 2020. URL : http://journals.openedition.org/assr/ 20858 ; DOI : https://doi.org/10.4000/assr.20858

Ce document a été généré automatiquement le 21 septembre 2020

(C) Archives de sciences sociales des religions 


\section{BERTRAND (Jean-René), MULLER (Colette), éds., Religions et territoires}

Paris, L'Harmattan, 1999, 290 p.

Danièle Hervieu-Léger

\section{RÉFÉRENCE}

BERTRAND (Jean-René), MULLER (Colette), éds., Religions et territoires, Paris,

L'Harmattan, 1999, $290 \mathrm{p}$.

1 Renouant avec une inspiration qui fut celle, en leur temps, de Gabriel Le Bras et d'Alphonse Dupront, huit géographes de l'équipe E.S.O. -Espaces Géographiques et Sociétés (U.M.R. C.N.R.S. no 6590), associés à des chercheurs de différentes universités étrangères (Espagne, Italie, Suisse, États-Unis, Roumanie) s'emploient à analyser les modalités de la présence du religieux dans la société et dans la culture à partir de son inscription territoriale. Cette approche - dont l'introduction de J.-R.B. présente les jalons théoriques et méthodologiques, repris et approfondis dans les introductions aux différentes parties de l'ouvrage - tend à saisir la manière dont des sociétés religieuses se sont constituées et se sont sédimentées dans la longue durée à partir et à l'intérieur d'une réalité locale qu'elles ont contribué à modeler. Plusieurs contributions relevant de la géographie historique se placent dans cette perspective. Mais l'approche par le territoire permet également de faire apparaître, à travers les remaniements contemporains de la localisation de la vie religieuse, les transformations et les recompositions de la religiosité elle-même. C'est là certainement l'aspect le plus novateur de l'ouvrage, servi par plusieurs contributions particulièrement bien documentées (celle de Dorothée Élineau, sur les recompositions paroissiales dans l'ouest de la France par exemple, ou encore celle de Jacques Palard sur le lien entre la paroisse catholique et le tissu socio-politique local). On regrette, cependant, que l'ensemble soit alourdi, sans profit majeur, par des présentations purement descriptives ou faiblement distanciées. Celles-ci, lorsqu'elles accordent une place 
excessive au discours autojustificatif des acteurs, sont portées à laisser dans l'ombre l'analyse des enjeux et conflits de territoire liés au développement de tel ou tel mouvement : c'est le cas, en particulier, de la contribution, richement documentée mais faiblement problématisée, portant sur le cas, pourtant fort intéressant à ce dernier point de vue, de la diffusion de la Communauté Saint-Jean créée par le Père MarieDominique Philippe.

2 Reste le dernier volet d'« interrogations ", consacré à la réflexion de quelques auteurs sur l'influence (éventuelle) de leur engagement chrétien sur le traitement de leurs dossiers. L'explicitation des points de vue en cette matière est certainement susceptible de faire progresser la réflexion épistémologique des chercheurs impliqués dans l'analyse scientifique des faits religieux. Mais on sait que la question principale demeure, en cette matière, et par-delà tous les efforts d'auto-analyse, celle du degré effectif d'intégration de cette réflexion épistémologique à la construction même des objets de recherche et à leur mise en perspective critique. 